\title{
Effect of sublingual nitroglycerin on cardiac performance in patients with coronary artery disease and non-dyskinetic left ventricular contraction
}

\author{
Thordur Hardarson ${ }^{1}$ and Kinsman E. Wright \\ From the Department of Medicine, Bayler College of Medicine and the Fondren-Brown Cardiovascular \\ Research and Training Center of the Methodist Hospital, Houston, Texas, U.S.A.
}

In 8 patients with coronary artery disease and symmetrical left ventricular contraction, an echocardiographic study of left ventricular function was performed before and 3 minutes after the administration of $0.6 \mathrm{mg}$ nitroglycerin sublingually. The left ventricular end-diastolic diameter decreased from $5 \cdot 2 \pm 0 \cdot 2$ to $4 \cdot 9 \pm 0 \cdot 2 \mathrm{~cm}$ $(P<0.05)$ and the end-systolic diameter from $4.2 \pm 0.2$ to $3.7 \pm 0.2 \mathrm{~cm}(P<0.001)$. The estimated stroke volume did not change significantly, while the cardiac output increased, $5 \cdot 8 \pm 0 \cdot 6$ to $7 \cdot 7 \pm 0.6 l$ min $^{-1}$ ( $P$ $<0.001)$ and the heart rate increased from $72 \pm 5$ to $90 \pm 6(P<0.001)$. The mean arterial blood pressure decreased from $105 \pm 4$ to $88 \pm 3 \mathrm{mmHg}(P<0 \cdot 001)$. The ejection fraction increased from $53 \pm 3$ per cent to $65 \pm 6$ per cent $(P<0.001)$ and the mean velocity of circumferential fibre shortening $\left(V_{C F}\right)$ from $0.81 \pm 0.05$ to $1 \cdot 15 \pm 0 \cdot 10$ circumferences per second $(P<0 \cdot 001)$. The estimated midsystolic midwall stress decreased from $155 \pm 14 \mathrm{~g} \mathrm{~cm}^{-2}$ to $102 \pm 12 \mathrm{~g} \mathrm{~cm}^{-2}$ after nitroglycerin $(P<0.001)$.

The administration of nitroglycerin was associated with a significant decrease in left ventricular preload and afterload. $A$ vasodilating effect is suggested by the fall in peripheral resistance. The overall improvement in ejection fraction and $V_{C F}$ may not reflect a true increase in contractility, because of the concomitant fall in wall stress.

\begin{abstract}
Although nitrites have been used for more than a century for the relief of angina pectoris (Brunton, 1867), there is still considerable controversy surrounding their exact mode of action. It is uncertain whether nitroglycerin acts chiefly by coronary vasodilatation (Fam and McGregor, 1964; Becker, Fortuin, and Pitt, 1971; Cohen et al., 1973; Goldstein, Stinson, and Epstein, 1973), or by the reduction of myocardial oxygen demands (Mason and Braunwald, 1965; Frick et al., 1968; Ganz and Marcus, 1972). The myocardial oxygen consumption is principally dependent on three variables, the left ventricular wall stress, the heart rate, and the contractile state of the heart (Braunwald, 1971). The left ventricular systolic wall stress, or afterload, is in turn determined by the intracavitary systolic blood pressure, chamber size, and wall thickness.

Echocardiography is a reliable method for Received 26 February 1976.

1 Present address: Department of Medicine, University Hospital, Reykiavik, Iceland.
\end{abstract}

estimating left ventricular minor axis, particularly in serial studies, using a patient as his own control (Pombo, Troy, and Russell, 1971; Fortuin et al., 1971; Gibson, 1973; Redwood, Henry, and Epstein, 1974). Though two recent investigations have shown a decrease in the echographic left ventricular dimension after nitroglycerin administration (DeMaria et al., 1974; Burggraf and Parker, 1974), no reports have been published about its effects on estimated wall stress in man. In the present study, changes in left ventricular afterload after nitroglycerin were estimated, using calculations based on a thick-wall spherical model of the chamber. This method probably allows a closer assessment of changes in myocardial oxygen demand than pressure and volume measurements alone. Changes in afterload can then be correlated with concurrent changes in heart rate and in the mean velocity of internal dimension shortening, used as an index of contractility, thus providing an estimate of all three major determinants of myocardial oxygen consumption. 
TABLE

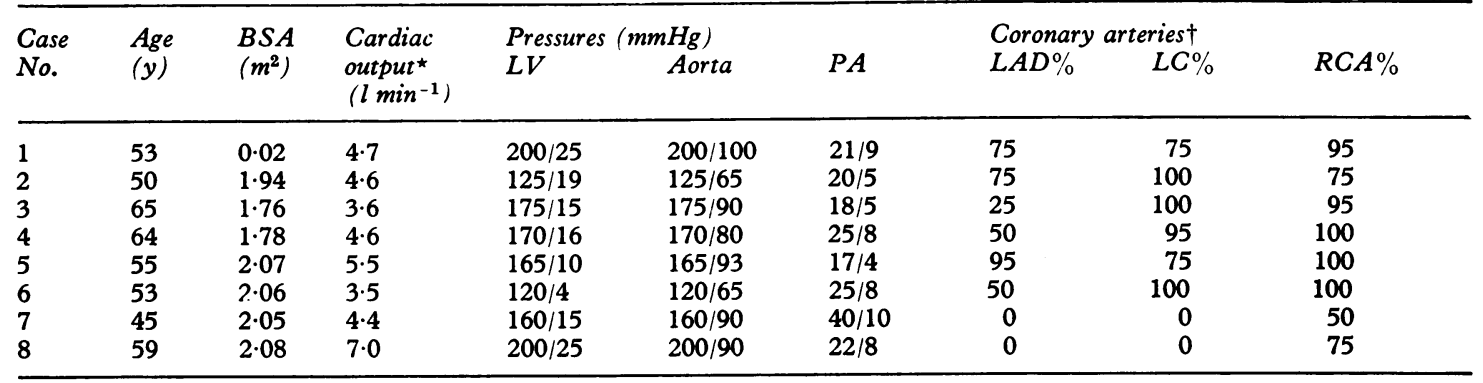

BSA, body surface area; LV, left ventricle; PA, pulmonary artery.

*The cardiac output was measured by the Fick method.

$\dagger$ The maximum percentage narrowings of the left anterior descending (LAD), left circumflex (LC), and right coronary arteries (RCA) are given.

\section{Patients and methods}

Eight men with ischaemic heart disease were selected for the study. Their ages ranged from 45 to 65 (Table). All had had cardiac catheterization less than a week before the non-invasive study. All the patients had symmetrical left ventricular contraction without dyskinetic areas. The relevant haemodynamic and angiographic data are presented in the Table. All the patients had previously used nitroglycerin successfully for angina pectoris. None was on digitalis or beta-adrenergic blocking agents at the time of the study.

For the echographic study, a Unirad 100 Series Diagnostic Echoscope was used with a Tektronix
174 strip-chart recorder. Standard procedures (Feigenbaum, 1973) were used for the identification and recording of the left ventricular dimension and posterior wall thickness. Simultaneously, an electrocardiographic lead showing clearly the onset of the QRS complex, an indirect carotid displacement curve, and a phonocardiogram, were recorded at a paper speed of $75 \mathrm{~mm} \mathrm{~s}^{-1}$ (Fig. 1). The phonotransducer was placed over the third intercostal space at the left sternal edge. The low cut-off phonofilter was set at $100 \mathrm{~Hz}$. The following systolic time intervals (STI) were calculated as described by Weissler, Harris, and Schoenfeld (1968): total electromechanical systole (QA2), left ventricular
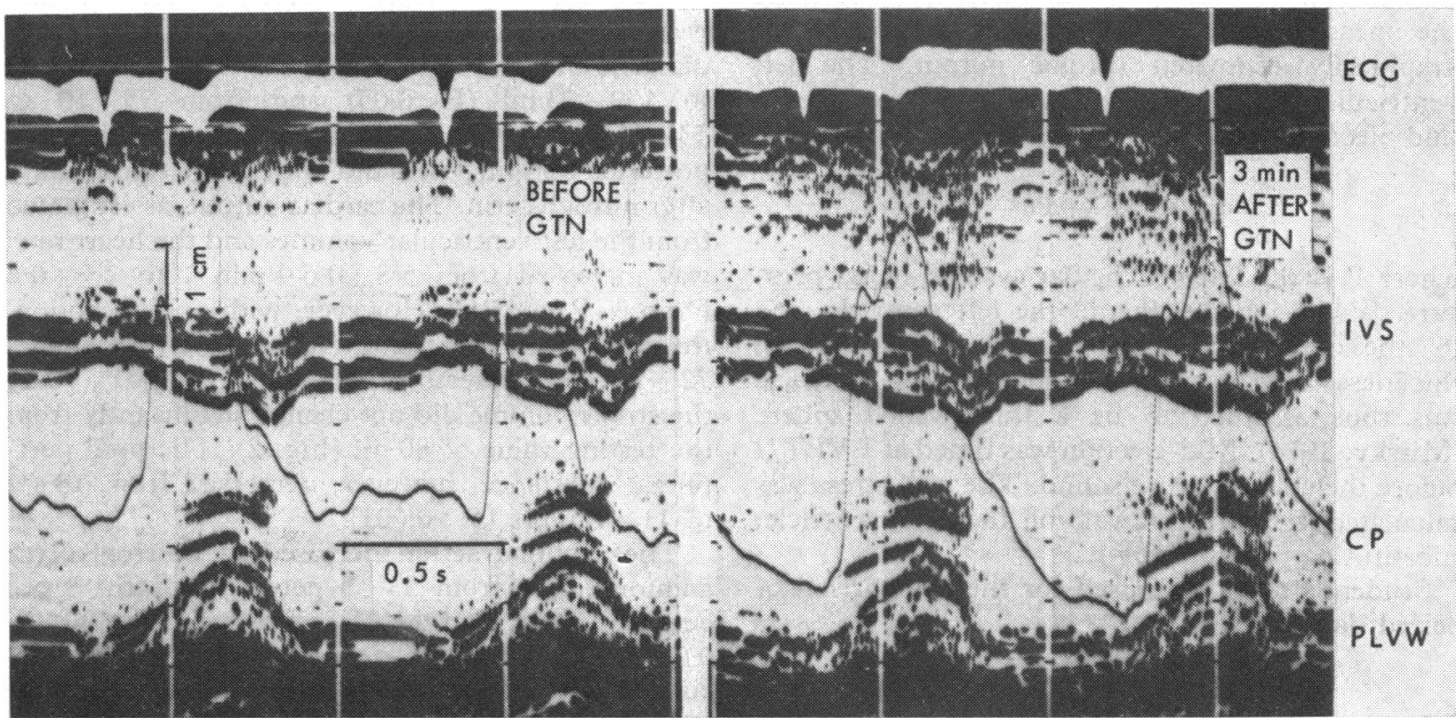

FIG. 1 Echocardiographic recordings of left ventricular dimension before and after the administration of sublingual nitroglycerin (GTN). ECG, electrocardiogram; IVS, interventricular septum; CP, carotid pulse; PLVW, posterior left ventricular wall. 
ejection time (LVET), and pre-ejection period (PEP). All the intervals were measured to the nearest $5 \mathrm{~ms}$ and the means of at least 5 cardiac cycles calculated.

Three control recordings were obtained during normal respiration, with the patients tilted at 20 degrees from the horizontal. The arterial blood pressure was measured twice with a sphygmomanometer. One nitroglycerin tablet $(0.6 \mathrm{mg})$ was given sublingually. Recordings were obtained at 10second intervals for 5 minutes and the blood pressure was measured at $30 \mathrm{~s}$ intervals. Care was taken to keep the position of the echotransducer constant during the study. The left ventricular end-diastolic dimension was measured $40 \mathrm{~ms}$ after the onset of the QRS complex and the end-systolic dimension at the time of minimum distance between the two endocardial surfaces. All the patients had normal septal motion.

The mean velocity of circumferential fibre shortening $\left(\mathrm{V}_{\mathrm{CF}}\right)$ was estimated as:

$$
\mathrm{V}_{\mathrm{CF}}=\frac{\mathrm{LVDD}_{\mathrm{L}} \mathrm{LVSD}}{\mathrm{LVDD} \times \mathrm{LVET}}\left(\text { circumferences s }^{-1}\right. \text { ) }
$$

where LVDD and LVSD represent the left ventricular end-diastolic and end-systolic dimensions. The left ventricular volume, stroke volume, and cardiac output were calculated as described by Fortuin et al. (1971). The mean arterial blood pressure was calculated as the diastolic blood pressure plus one-third of the pulse pressure. The total peripheral resistance was obtained by dividing the mean arterial blood pressure by the echographically estimated cardiac output. The left ventricular wall stress $(\sigma)$ was estimated during mid-ejection from the equation:

$$
\sigma=\frac{1+b^{3} / 2 r^{3}}{b^{3}-a^{3}} P^{3}
$$

where $\mathbf{P}$ is the left ventricular systolic blood pressure, ' $a$ ' the inner radius of the left ventricle, and ' $b$ ' the outer radius, i.e. ' $a$ ' plus posterior wall thickness. The geometrical shape of the ventricle was thus assumed to be a thick-walled sphere (Mirsky, 1974). Mid-ejection was timed at LVET/2 before the aortic closure sound. The wall stress was calculated for the midwall of the left ventricle, substituting $(a+b) / 2$ for $r$.

Student's t-test was used for the comparison of paired data.

\section{Results}

The results given are those for the control period and for 3 minutes after the administration of nitroglycerin, when the maximal changes in heart rate,

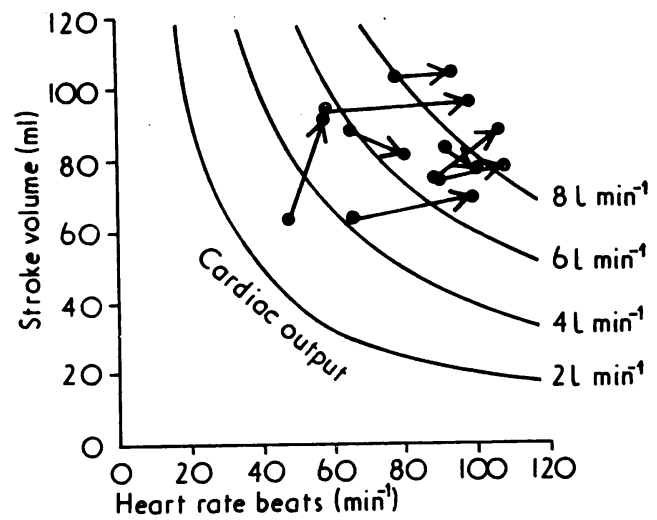

FIG. 2 Changes in heart rate, stroke volume, and cardiac output, after nitroglycerin.

arterial blood pressure, and left ventricular dimension occurred.

The systolic blood pressure decreased from $142 \pm 7$ (SEM) $\mathrm{mmHg}$ in the control period to $116 \pm 7 \mathrm{mmHg}(P<0.001)$ and the diastolic pressure from $84 \pm 3$ to $74 \pm 2 \mathrm{mmHg} \quad(P<0.001)$. The calculated mean blood pressure also decreased significantly, from $105 \pm 4$ to $88 \pm 3 \mathrm{mmHg}$ $(P<0.001)$. The end-diastolic and end-systolic dimensions of the left ventricle both decreased significantly, from $5 \cdot 2 \pm 0 \cdot 2 \mathrm{~cm}$ to $4.9 \pm 0.2 \mathrm{~cm}$ $(P<0.05)$, and from $4.2 \pm 0.2 \mathrm{~cm}$ to $3.7 \pm 0.2 \mathrm{~cm}$ $(\mathrm{P}<0.001)$, respectively. Corresponding changes were seen in the calculated left ventricular enddiastolic and end-systolic volumes, from $155 \pm 15 \mathrm{ml}$ to $139 \pm 13 \mathrm{ml} \quad(P<0.05)$ and from $75 \pm 10$ to $53 \pm 11(P<0.001)$, respectively. The end-diastolic posterior wall thickness did not change significantly after nitroglycerin. The cardiac output, as estimated from the left ventricular volumes and the heart rate, was increased from $5.8 \pm 0.61 \mathrm{~min}^{-1}$ to $7.7 \pm 0.6$ $1 \mathrm{~min}^{-1}(P<0.001)$. However, with one exception, this was the result of an increase in heart rate from $72 \pm 5$ to $90 \pm 6$ beats per minute $(P<0.001)$, while the stroke volume did not change significantly from the resting value of $80 \mathrm{ml}$ (Fig. 2). The total peripheral resistance, however, decreased from $18 \pm 4$ to $11 \pm 1$ units $(P<0.001)$.

The ejection fraction increased after nitroglycerin administration from $53 \pm 3$ per cent to $65 \pm 6$ per cent $(P<0.001)$ and the $V_{C F}$ increased from $0.81 \pm$ 0.05 to $1.15 \pm 0.10$ circ s$^{-1}(P<0.001)$. The calculated midsystolic midwall stress decreased from $155 \pm 14$ to $102 \pm 11 \mathrm{~g} \mathrm{~cm}^{-2}(\mathrm{P}<0.001)$. No significant changes were seen in the rate corrected systolic time intervals: LVETI was $400 \pm 9$ before and $390 \pm 6$ at 3 minutes after nitroglycerin; PEPI 
was $141 \pm 3$ and $143 \pm 3$ and QA2I was $542 \pm 8$ and $531 \pm 6$ before and after nitroglycerin.

\section{Discussion}

Recently, interest has been growing in the use of agents which decrease left ventricular afterload for the treatment of patients with myocardial infarction (Franciosa et al., 1974; Hirshfeld et al., 1974) or contraction abnormalities in chronic ischaemic heart disease (Helfant et al., 1974; Dove, Shah, and Schreiner, 1974). In the present study, echocardiographic techniques were used for the estimation of afterload as expressed by the left ventricular wall stress, before and after the administration of nitroglycerin. These changes in afterload can be related to the attendant variations in $\mathrm{V}_{\mathrm{CP}}$ (Fig. 3). Since the long axis of the left ventricle cannot be measured echocardiographically, a thick-wall spherical model is assumed, and the formula used allows estimations of wall stress to be made at any given level through the wall thickness. This model can, however, only be applied to symmetrically contracting ventricles. Ratshin, Rackley, and Russell (1974) have shown that when left ventricular wall stress is calculated, using intracavitary pressure recordings with measurements of left ventricular dimension by echocardiography and by simultaneous angiography, similar results are obtained by both techniques. When intracardiac pressure recordings are not available, only the peak systolic blood pressure,

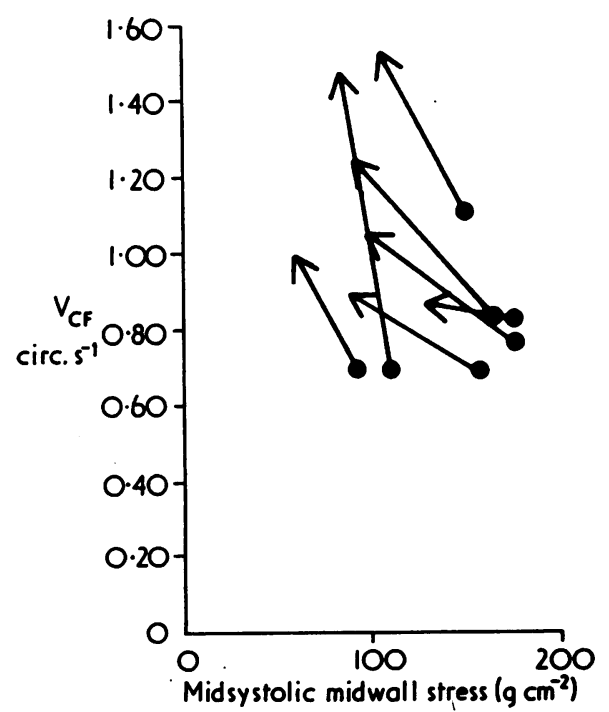

FIG. 3 Changes in the velocity of circumferential fibre shortening $\left(V_{C F}\right)$ and midsystolic midwall stress after nitroglycerin. measured sphygmomanometrically, can be used. The peak systolic pressure is assumed to occur at mid-ejection and the left ventricular dimension can be estimated at this moment as described above.

Although the peak left ventricular wall stress usually occurs early in systole, the wall stress at mid-ejection is probably comparable in any individual patient before and after acute interventions. If the wall stress falls nearly linearly from an early systolic peak (Mirsky, 1968), the midsystolic measurement can be used as an approximate measure of the mean systolic stress and therefore correlated with the mean velocity of circumferential fibre shortening.

In spite of the usually reported good correlations between echocardiographic and angiocardiographic left ventricular dimensions, there is considerable scatter at all levels (Fortuin et al., 1971; Gibson, 1973). The wide confidence margins are reflected in the absolute values for wall stress. However, recent studies (Redwood et al., 1974) have supported the use of echocardiographic left ventricular dimensions in the study of the effects of haemodynamic interventions. In the present context, directional changes in wall stress are emphasized.

Fig. 3 shows that in all the patients, a decrease in left ventricular afterload was accompanied by an increase in $V_{C P}$, thus illustrating a modified forcevelocity relation. With decreased afterload and total peripheral resistance, the increased $V_{C F}$ cannot be attributed to increased left ventricular contractility, even though the left ventricular end-diastolic volume was decreased. Isolated muscle studies (Zelis et al., 1970a, b) have failed to show any alteration in contractility after moderate doses of nitroglycerin. However, in man, nitroglycerin may elicit reflex sympathetic activity as a result of its vasodilator action (Zelis et al., 1970a, b). In a recent study, DeMaria et al. (1974), reported a small decrease in $\mathrm{V}_{\mathrm{CF}}$ after nitroglycerin. In that study, however, left ventricular ejection time was measured from the beginning of the QRS complex to the time of maximal anterior position of the posterior left ventricular wall, assuming a pre-ejection period of $50 \mathrm{~ms}$. This method is probably less reliable than that using the indirect carotid tracing; the implied prolongation of left ventricular ejection time after nitroglycerin is also at variance with results of this and previous studies (Sawayama et al., 1973). Redwood et al. (1974) found an increase in $V_{C F}$ from 1.3 to 1.7 circ s $^{-1}$ in their normal subjects, a change similar to that observed in our patients. The increase in cardiac output found in the present study exceeds the insignificant increases observed by DeMaria et al. (1974), and Burggraf and Parker 
(1974). The changes in cardiac output are probably largely determined by the relative predominance of venous or arteriolar dilatation (Mason and Braunwald, 1965). A dominant arteriolar depressant effect is likely in our group of patients.

Opinion is still divided as to whether nitroglycerin relieves angina pectoris mainly by its effect on left ventricular pump function or by coronary vasodilatation (Cohn and Gorlin, 1974). In 1867, Brunton reported after Gamgee that amyl nitrite 'greatly lessens the arterial tension both in animals and man ... which led me to try it in angina pectoris'. The present study confirms earlier reports (Brachfeld, Bozer, and Gorlin, 1959; DeMaria et al., 1974; Burggraf and Parker, 1974) that arterial pressure and left ventricular dimensions are decreased after nitroglycerin, both effects combining to produce a sharp decrease in afterload or wall stress. Preload, as reflected by the left ventricular end-diastolic dimension, is also significantly reduced. Directional changes in myocardial oxygen consumption cannot be predicted from these data, since its main determinants are changed in opposite directions. It is likely, nevertheless, that the abrupt fall in wall tension would override changes having a contrary effect, producing a net decrease in myocardial oxygen requirements. This effect alone, regardless of possible increases in coronary blood flow, might successfully relieve angina pectoris in many patients. However, there is some evidence (Kjekshus, 1973) that a reduction of left ventricular preload may by itself improve coronary blood flow to underperfused subendocardial areas. Both the postulated mechanisms of action of nitroglycerin may, therefore, be operating.

\section{References}

Becker, L. C., Fortuin, N. J., and Pitt, B. (1971). Effect of ischemia and antianginal drugs on the distribution of radioactive microspheres in the canine left ventricle. Circulation Research, 28, 263.

Brachfeld, N., Bozer, J., and Gorlin, R. (1959). Action of nitroglycerin on the coronary circulation in normal and mild cardiac subjects. Circulation, 19, 697.

Braunwald, E. (1971). Control of myocardial oxygen consumption: physiologic and clinical considerations. American fournal of Cardiology, 27, 416.

Brunton, T. L. (1867). Use of nitrite of amyl in angina pectoris. Lancet, 2, 97.

Burggraf, G. W., and Parker, J. O. (1974). Left ventricular volume changes after amyl nitrite and nitroglycerin in man as measured by ultrasound. Circulation, 49, 136.

Cohen, M. V., Downey, J. M., Urschel, C. W., Sonnenblick, E. H., and Kirk, E. S. (1973). Enhancement of myocardial contractility by dilation of coronary collaterals (abstract). American fournal of Cardiology, 31, 126.

Cohn, P. F., and Gorlin, R. (1974). Physiologic and clinical actions of nitroglycerin. Medical Clinics of North America, $58,407$.

DeMaria, A. N., Vismara, L. A., Auditore, K., Amsterdam, E. A., Zelis, R., and Mason, D. T. (1974). Effects of nitroglycerin on left ventricular cavitary size and cardiac performance determined by ultrasound in man. American Fournal of Medicine, 57, 754.

Dove, J. T., Shah, P. M., and Schreiner, B. F. (1974). Effects of nitroglycerin on left ventricular wall motion in coronary artery disease. Circulation, 49, 682.

Fam, W. M., and McGregor, M. (1964). Effect of coronary vasodilator drugs on retrograde flow in areas of chronic myocardial ischemia. Circulation Research, 15, 355.

Feigenbaum, H. (1973). Echocardiography. Lea and Febiger, Philadelphia.

Fortuin, N. J., Wood, W. P., Jr., Sherman, M. E., and Craige, E. (1971). Determination of left ventricular volumes by ultrasound. Circulation, 44, 575.

Franciosa, J. A., Guiha, N. H., Limas, C. J., Paz, S., and Cohn, J. N. (1974). Arterial pressure as a determinant of left ventricular filling pressure after acute myocardial infarction. American fournal of Cardiology, 34, 506.

Frick, M. H., Balcon, R., Cross, D., and Sowton, E. (1968). Hemodynamic effects of nitroglycerin in patients with angina pectoris studied by an atrial pacing method. Circulation, 37, 160.

Ganz, W., and Marcus, H. S. (1972). Failure of intracoronary nitroglycerin to alleviate pacing-induced angina. Circulation, 46, 880.

Gibson, D. G. (1973). Estimation of left ventricular size by echocardiography. British Heart fournal, 35, 128.

Goldstein, R. E., Stinson, E. B., and Epstein, S. E. (1973). Effects of nitroglycerin on coronary collateral function in patients with coronary occlusive disease (abstract). American fournal of Cardiology, 31, 135.

Helfant, R. H., Pine, R., Meister, S. G., Feldman, M. S., Trout, R. G., and Banka, V. S. (1974). Nitroglycerin to unmask reversible asynergy: correlation with post coronary bypass ventriculography. Circulation, 50, 108.

Hirshfeld, J. W., Jr., Borer, J. S., Goldstein, R. E., Barrett, M. J., and Epstein, S. E. (1974). Reduction in severity and extent of myocardial infarction when nitroglycerin and methoxamine are administered during coronary occlusion. Circulation, 49, 291.

Kjekshus, J. K. (1973). Mechanism for flow distribution in normal and ischemic myocardium during increased ventricular preload in the dog. Circulation Research, 33, 489.

Mason, D. T., and Braunwald, E. (1965). The effects of nitroglycerin and amyl nitrite on arteriolar and venous tone in the human forearm. Circulation, 32, 755.

Mirsky, I. (1968). Left ventricular stresses in the intact human heart. Biophysical fournal, 9, 189.

Mirsky, I. (1974). In Cardiac Mechanics. Ed. by I. Mirsky, D. N. Ghista, and H. Sandler. Wiley, New York.

Pombo, J. F., Trey, B. L., and Russell, R. O., Jr. (1971). Left ventricular volumes and ejection fraction by echocardiography. Circulation, 43, 480.

Ratshin, R. A., Rackley, C. E., and Russell, R. O., Jr. (1974). Determination of left ventricular preload and afterload by quantitative echocardiography in man. Circulation Research, 34, 711.

Redwood, D. R., Henry, W. L., and Epstein, S. E. (1974). Evaluation of the ability of echocardiography to measure acute alterations in left ventricular volume. Circulation, 50, 901 .

Sawayama, T., Tohara, M., Katsume, H., and Nezuo, S. (1973). Polygraphic studies of the effect of nitroglycerin in patients with ischaemic heart disease. British Heart fournal, 35, 1234. 
Weissler, A. M., Harris, W. S., and Schoenfeld, C. D. (1968). Systolic time intervals in heart failure in man. Circulation, 37, 149.

Zelis, R., Amsterdam, E. A., and Mason, D. T. (1970a). Alterations in ventricular contractility produced by nitroglycerin in man. American fournal of Cardiology, 26, 667. Zelis, R., Mason, D. T., Spann, J. F., and Amsterdam, E. A. (1970b). The mechanism of action of nitroglycerin in the relief of angina pectoris: reduction of myocardial oxygen requirements by extracoronary vasodilation and its attenuation by the chronic administration of isosorbide dinitrate (abstract). Annals of Internal Medicine, 72, 779.

Requests for reprints to Dr. T. Hardarson, Department of Medicine, University Hospital, Reykjavik, Iceland. 